\title{
Expressões da mulher na dramaturgia do teatro operário anarquistas
}

Ana Ribeiro Grossi Araújo ${ }^{1}$ Fabiana Lazzari de Oliveira ${ }^{2}$

Rosimeire Da Silva ${ }^{3}$

Vera Collaço ${ }^{4}$

O presente artigo analisa, a partir das questões do anarquismo referentes às mulheres, três peças dramatúrgicas do livro Antologia do Teatro Anarquista, de

Maria Thereza Vargas: O Semeador de Avelino Fóscolo, A Bandeira Proletária de Marino Spagnolo e Uma Mulher Diferente de Pedro Catallo. Inicialmente, apresentam-se alguns ideais do movimento anarquista e da vertente chamada anarcofeminista, da virada do século XIX para o século XX, mostrando a luta e a importância da mulher no mesmo. Em seguida, a análise dos textos demonstra a expressão dos ideais anarquistas apresentados, assim como a percepção que as peças nos mostram sobre a realidade da época. Esses traços aparecem ora explícitos, ora implícitos nas características das personagens, no enredo, nos diálogos, nas rubricas e demais aspectos estruturais das peças. A importância que a expressão desses ideais tem nessas peças atesta o fato já conhecido de que

o teatro era um dos principais meios para se despertar a consciência social, o veículo de uma educação popular para a conscientização libertária.

Palavras-chaves: Anarquismo; Anarcofeminismo; Teatro didático; Teatro operário.

\section{Abstract}

his article analyses the dramaturgy of three plays in Maria Thereza Vargas's book Antologia do Teatro Anarquista: O Semeador ("The Sower"), by Avelino Fóscolo, A Bandeira Proletária ("The Proletarian Flag"), by Marino Spagnolo, and Uma Mulher Diferente ("A Diferent Woman"), by Pedro Catallo. This analysis takes as a starting point the anarchist issues related to women. The introduction presents some of the ideals of the anarchist movement and one of its trends in the late XIX and early XX century, the anarcho-feminism. The aim is to emphasize women's struggle and their importance in that movement. The main section focuses on an analysis of the texts, which shows the expression of the presented anarchist ideals, as well as a perception of the reality of that moment. This expression appears both as implicit and explict elements of the characters, dialogues, plot, actions and other structural features of the plays.

The importance that the expression of those ideals in the plays proves the stablished assuption that theatre was one of the main forms to raise social consciousness, the vehicle for popular education and for raising a libertarian consciousness.

Keywords: Anarchism; Anarchic-feminism; Didactic theatre; Worker's theatre.

\footnotetext{
1 Doutoranda em Letras/Tradução pelo PGET - Universidade Federal de Santa Catarina - UFSC

2 Doutoranda em Teatro pelo PPGT - Universidade do Estado de Santa Catarina - UDESC

3 Mestra em Teatro pelo PPGT - Universidade do Estado de Santa Catarina - UDESC

4 Professora Doutora do Departamento de Artes Cênicas e do Programa de Pós-Graduação em Teatro da UDESC.
} 
A arte sem uma finalidade social e humana perde todo o valor como arte lucrando em valor comercial e industrial.

(Arsênio Palácios, 1917)

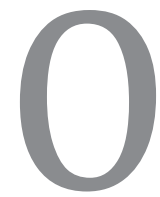

teatro operário como um todo, no início do século $X X$, foi muito atuante, e extremamente representativo dos anseios políticos do proletariado, mas também do imaginário que se constituía simultaneamente à consolidação de uma sociedade industrial no Brasil. O teatro anarquista não é exceção: trazia as questões anarquistas, em atrito com o mesmo universo que estava em pauta no teatro sindicalista, comunista e outros. No Brasil, Maria Thereza Vargas (1929) recentemente editou Antologia do Teatro Anarquista com três textos pertencentes a um mesmo movimento teatral: o teatro operário anarquista da primeira metade do século XX, livro de grande importância, já que é o único que retrata a dramaturgia da época.

Interessa-nos, neste momento, trabalhar com um recorte específico desse universo: o imaginário referente às mulheres, as questões do anarquismo que concernem às mulheres e, especificamente, as questões anarcofeministas. Em cada um dos três textos da Antologia do Teatro Anarquista de Maria Thereza Vargas - O Semeador, A Bandeira Proletária e Uma Mulher Diferente - essas questões apresentam-se de maneira diferenciada. Vale ressaltar que os textos são de diferentes autores e de diferentes regiões do Brasil. No entanto, antes de apresentar essa análise dos textos dramatúrgicos, problematizaremos alguns pontos sobre o movimento anarquista.

A ideologia do anarquismo tem por meta a organização de uma sociedade fundada no livre entendimento, na qual cada indivíduo pode atingir o máximo de desenvolvimento possível, em aspectos materiais, morais e intelectuais. $\mathrm{O}$ amor livre é propagado, e a solidariedade social leva à cooperação e fraternidade entre todas as pessoas, com ações diretas e apoio mútuo, independente de sexo, etnia, e evidente- mente sem estratos sociais.

A palavra anarquia vem do grego anarkhia e significa ausência de governo. Segundo Enrico Malatesta (1853-1932), um dos filósofos do anarquismo, anarquia é o "estado de um povo que surge sem autoridade constituída, sem governo" (Malatesta, 2001, p. 11). Ao contrário da crença popularmente difundida que associa a palavra "anarquia" a "confusão, desordem" (como se pode perceber nos dicionários de língua portuguesa, por exemplo), a crença libertária anarquista consiste na revolução universal, que deve iniciar-se pela educação de todos, através da conscientização da importância de sua emancipação.

O anarquismo é um movimento filosófico composto por várias correntes que têm como princípio a liberdade do indivíduo e defendem o fim da existência de qualquer forma de autoridade. Defende, prioritariamente, uma ação revolucionária pelo fim da autoridade do Estado, do Clero e do Capitalismo. Entretanto, como ele não poderia ter um único viés, não pode ser visto como um dogma, mas sim, como um movimento que gera transformações em seus diferentes contextos e momentos históricos ${ }^{5}$.

Inspirado pela ideia de liberdade defendida durante a Revolução Francesa e surgido paralelamente ao comunismo, o anarquismo vai além em suas propostas: de liberdade, tomada radicalmente pela anulação de qualquer instância de poder e autoridade; e também de coletivismo, que não pressupõe, como no comunismo, a propriedade coletiva, mas sim a ausência de propriedade.

Max Nettlau (1865-1943), um dos mais importantes historiadores e arquivistas do anarquismo, afirmou que as várias correntes de pensamento e ação anarquistas são como a evolução do anarquismo (enquanto teoria e prática) ao longo da sua histó-

\footnotetext{
5 Entre os mais influentes pensadores do anarquismo, podemos encontrar os nomes de: Willian Goldwin (1756-1936); Robert Owen (1771 - 1858); Charles Fourier (1772 - 1837); Pierre Joseph Proudhon. (1809 - 1895);Piotr Alexeyevich Kropotkin (18421921); Lev NikolayevichTolstoi (1828 -1910); Mikhail Aleksandrovitch Bakunin (18141876); Francisco Ferrer Guadian (1859-1909); Enrico Malatesta (1853-1932);Luigi Damiani (1876-1953); Gregório Nazianzeno Moreira de Queirós Vasconcelos - Neno Vasco - (1878-1923). Entre os brasileiros podemos citar: José Rodrigues Leite e Oiticica (1882-1957) e Edgard Frederico Leuenroth (1881-1968).
} 
ria e a forma própria do movimento em cada localidade. Entre essas vertentes: o anarcoindividualismo, anarcossindicalismo, anarcocomunismo, anarcocoletivismo, anarcofeminismo. Porém, não devemos observá-las de maneira sectária, fragmentada, pois todas elas dialogam entre si, e os anarquistas procuraram, em sua maioria, caminhar juntos nas movimentações enquanto as diferenças não falaram mais alto.

$\mathrm{O}$ anarquismo propõe a transformação total da sociedade, ou seja, a transformação das relações pessoais, sociais e cotidianas, acarretando o progresso e a evolução da humanidade. Nesse sentido, o pensamento das mulheres anarquistas vai mais longe do que o de muitos dos teóricos do anarquismo do sexo masculino. Elas propõem bases teóricas do anarquismo como meio para emancipação da mulher, que não existe sem a emancipação da humanidade: a educação sexual e libertária; o amor livre; a maternidade livre e consciente como fruto da vontade da mulher; a livre união; a crítica ao casamento monogâmico e contratual burguês, e às relações hierárquicas existentes no próprio movimento anarquista, principalmente no que se refere às hierarquias com relação aos sexos, apontando e criticando o machismo da sociedade, presente igualmente nos meios operários.

$\mathrm{Na}$ virada do século XIX para o XX a burguesia ditava comportamentos para as mulheres, e as destinava para funções exclusivas de mãe e esposa. Esses modelos foram questionados por muitas mulheres: a mulher moderna era aquela que não se ocupava só do lar e da família, mas também de uma carreira, da aparência e da convivência social. As mulheres estavam nas ruas e muitas trabalhavam nas mais distintas atividades. Assim, havia mulheres que lutaram cotidianamente pela sua liberdade e autonomia na sociedade, e exerceram-nas em seus espaços de luta, trabalho ou lazer, sendo agentes e não se sujeitando a normas e padrões.

Entre as mulheres anarquistas que traziam suas questões feministas podemos citar a francesa Louise Michel (1830-1905); a lituana Emma Goldman (1869-1940); a estadunidense Voltairine de Cleyre (18661912); a brasileira Maria Lacerda de Moura (1887-1945). Foram elas, segundo Samantha Mendes (2010), que apresentaram uma nova vertente ao anarquismo, dando um novo enfoque - o anarcofeminismo, que não só defendia as premissas já citadas, como criticavam o feminismo liberal e sua luta pela inserção da mulher na sociedade capitalista, isto é, uma critica também ao capitalismo e sua ideologia liberal. Outras brasileiras libertárias são: Izabel Cerruti, Leda Rafaxelli, Canda Otero, Matilde Magrassi e Ilia, Anna de Castro Osório e Angelina Soares. $\mathrm{O}$ que pode ser constatado historicamente é que pouco ou nada se sabe sobre a vida dessas ativistas brasileiras, o que se tem são os registros de seus escritos nos jornais libertários, sendo estes os materiais que podem apresentar o pensamento e ideais aplicados em suas militâncias:

Essas mulheres propuseram o anarquismo como única forma de libertação total da mulher e lutaram para criar uma vida totalmente livre através da destruição do capitalismo e da construção de uma sociedade baseada em valores de solidariedade e fraternidade entre todos os indivíduos (Mendes, 2010, p. 181).

São mulheres que acreditavam no anarquismo como a possibilidade mais completa para a emancipação e libertação da mulher de sua condição de submissa propagada pela moral burguesa. As ideias e teorias dessas libertárias estão diretamente atreladas a suas experiências cotidianas como mulheres, no entanto encontram-se compartilhadas e apoiadas por muitos homens libertários. Essas anarcofeministas propunham a construção de uma sociedade mais justa e igualitária, rompendo com qualquer relação sexista, assim como questionando a moral burguesa e os papéis oferecidos à mulher na sociedade: [...] "a meu ver [...] qualquer dependência, qualquer coisa que destrua a total autonomia de um indivíduo, assemelha-se à escravi- 
dão" (Cleire, 2001, p. 26). A ideia anarcofeminista é criar uma comunidade de seres humanos livres e solidários entre si:

A luta da mulher pela libertação, portanto, não seria somente uma luta para libertar-se de algumas tradições e laços burgueses e exercer uma nova prática de si, mas sim uma luta pela destruição da sociedade capitalista, com todas as suas tradições e valores, a partir de si própria (rompendo em sua vida cotidiana com os valores que inferiorizam a mulher). (Mendes, 2012, p.174)

Os princípios anarquistas sustentam a educação como ação libertária para a emancipação. De acordo com as anarcofeministas, não há emancipação feminina sem emancipação da humanidade. Assim, propõe aplicar a educação na emancipação intelectual da mulher. Outro ponto diz respeito à classe trabalhadora como agente na organização da sociedade anárquica, na qual deve ser extinta a exploração de um ser humano por outro ser humano. Também valorizam a cultura e a arte como importante instrumento revolucionário, como meio de educação. Propõem que a educação popular seja de caráter social, com conteúdos científicos, filosóficos e artísticos como ferramentas na transformação social.

\section{O teatro como instrumento de transformação social}

O teatro era entendido, no final do século XIX e princípio do século XX, como um dos principais meios para se despertar a consciência social, o veículo de uma educação popular para a conscientização libertária, de modo que houvesse o desenvolvimento da "consciência de uma existência livre" (Nettlau, 2008, p. 27) em que os fundamentos autoritários seriam contestados e os sentimentos de solidariedade social exaltados. Ou seja, uma maneira de se propagar os princípios anarquistas com um ensino alternativo em relação ao institucionalizado.

Nesse sentido, muitos anarquistas acreditavam na força dessa linguagem artística como meio de propagar suas ideias, assim livres de pressões históricas e estéticas. $O$ fator principal das encenações era o conteúdo, "a mensagem a ser passada àqueles que assistiam e participavam de determinada expressão artística, e não a estética na arte, assim a experiência e o alcance final era mais importante do que a própria obra" (Mendes, 2010, p. 219). Percebe-se na proposição anarquista que a estética ficava em segundo plano, o mais importante era a mensagem dos espetáculos. Esse teatro político e didático privilegiava as ideias anarquistas, e estava carregado de crítica social. E como bem observa Gabriel Passetti (2000): "Em todas as peças representadas o ponto de vista era o do operário, mostrando principalmente o cotidiano desta população: greve, delação, relação empregador-empregado e a condenação de um estado de apatia da classe com relação às desigualdades sociais". Esse contexto e situações são o que podemos ver, por exemplo, nas peças que agora passaremos a analisar, observando-os pelo ângulo da visão feminista.

\section{O Semeador, de Avelino Fóscolo}

O primeiro texto da Antologia é $O$ Semeador, drama social em três atos. Publicado pela primeira vez em 1921 (e, possivelmente, encenado anos antes), na jovem capital do estado de Minas Gerais, o texto de autoria de Avelino Fóscolo ${ }^{6}$ (1864-1944) trata da construção de uma sociedade anarquista ideal. Embora dirigida à classe operária, a peça se passa em contexto agrário: numa fazenda governada por um Coronel, figura tradicional na política brasileira até meados do século XX. O retorno do filho que saíra para estudar na Europa causa a reviravolta versado nas experiências anarquistas eu-

\footnotetext{
6 Segundo Vargas (2009, p. XIII) "Fóscolo é uma das personalidades mais curiosas do movimento anarquista no Brasil. Para fugir das Minas de Morro Velho, engajou-se numa companhia teatral dirigida pelo americano Keller, cuja função era viajar apresentando quadros vivos. Encantou-se pelo teatro e pouco depois foi contratado por uma companhia portuguesa dirigida por certo Antônio Fernal." Representou textos alheios e seus próprios, assim como escreveu a primeira peça, a opereta Os Estrangeiros. Dedicou-se a instrução do povo e editou o jornal Nova Era, pregando o Anarquismo, a partir de textos de Mikhail Bakunin e Piotr Kropotkin. Formou uma biblioteca e convidava a população a ler jornais que assinava, bem como seus autores preferidos: Émile Zola, Victor Hugo, Eça de Queirós e Júlio Verne. Ergueu um palco onde abrigou o "Club Dramático e Literário".
} 
ropeias, esse novo herdeiro que se torna administrador, encarregado da fazenda pelo próprio pai, provoca a transformação daquela comunidade, que abandona a estrutura aristocrática por uma nova forma de trabalho, mais produtiva, não hierárquica e não exploratória, nem da natureza nem do ser humano. Nesse contexto, há uma única personagem mulher em cena: Laura.

$\mathrm{Na}$ personagem Laura, podem-se perceber as duas questões principais colocadas pelos anarquistas em relação às mulheres, e enfatizadas pelas anarcofeministas: 0 direito da mulher à educação, e o direito ao amor livre, em oposição ao casamento burguês. Outra questão, desenvolvida paralelamente, é a lealdade ao companheiro na causa revolucionária.

Laura é filha do feitor, Roberto, e tem o amor do jovem patrão, Júlio. Seu pai deu a ela a oportunidade de estudar, que ela retribui alfabetizando as crianças pobres. $\mathrm{O}$ discurso de Laura oscila entre a defesa dos velhos costumes aristocráticos, por herança, e a consciência racional dos ideais de justiça social do anarquismo, adquirida por si mesma em decorrência de seus estudos e aprofundada no convívio com Júlio, o anarquista recém-chegado. É perceptível, na trajetória da personagem, um progresso no sentido da firmeza de seu discurso anarquista e no enfrentamento do discurso aristocrático.

Em sua primeira aparição na peça, Laura conversa com o pai, Roberto, que estranha o comportamento de Júlio:

ROBERTO- Como modificam a gente as terras estrangeiras... Abraçou a todos nós, mesmo os negros, os libertos e não consentiu que o carregassem. Chama a todos de amigos, como se fôssemos farinha do mesmo saco. (Fóscolo apud Vargas, 2009, p.16)

Laura, a princípio, concorda em parte com o pai:

LAURA - Quando é bem superior a todos nós, pela ilustração ao menos. (ibidem) Ainda na mesma cena, entretanto, frente à submissão do pai aos prin- cípios aristocráticos de obediência, chega a afirmar:

LAURA - E assim vão os pequenos, e são a maioria, deixando-se salpicar de lama, aterrorizados e ofuscados pelo ídolo de ouro. (ibidem)

Na cena seguinte, entretanto, diante de Júlio, Laura vacila em suas certezas, colocando-se inferior ao patrão, rico e estudado:

LAURA - Como eu? Pobre de mim, simples camponesa dedicada aos trabalhos domésticos e aos cuidados aos velhos pais, que mérito posso ter? (idem, p.20)

É Júlio, então, que, em seu discurso, vai sedimentando em Laura a consciência de princípios anarquistas tais como: a igualdade entre os seres humanos, inclusive a igualdade entre os sexos; o respeito mútuo; o direito de todo ser humano ao produto do trabalho conforme suas necessidades, e a importância da educação. Laura, a princípio, ressalta seu desconhecimento das novas ideias trazidas por Júlio:

LAURA - Há em suas palavras algo de misterioso e novo que não compreendo. (idem, p. 22)

No decorrer do texto, veremos Laura fortalecida enfrentar os patrões, argumentando contra os impropérios do Coronel:

LAURA - Mas as suas palavras não me farão recuar na ascensão libertária, porque me sinto forte para desprezá-las como desprezo esse ouro esbulhado ao mísero proletário. (idem, p. 66)

E, na cena final, ela assume deliberadamente o discurso revolucionário, afirmando sobre a nova sociedade que começa a se construir ali:

LAURA - É a realização de um paraíso que o homem há de conquistar á força de trabalho e á força de saber. (idem, p.85) 
A conscientização de Laura para a causa anarquista decorre de sua predisposição a uma visão racional da sociedade, impulsionada em parte por sua educação, anterior à chegada de Júlio. Laura não apenas é letrada, como atua no letramento de crianças.

$\mathrm{O}$ direito de todas as pessoas à educação é uma preocupação central para o anarquismo. Para que exista uma sociedade livre, todos os seus membros devem ter acesso à informação e serem capazes de pensamento reflexivo-crítico.

$\mathrm{O}$ anarcofeminismo apropria-se dessa ideia, acrescentando que a emancipação feminina também depende fundamentalmente da educação, com ênfase para a educação das próprias mulheres. Conforme publica Maria Lacerda de Moura, em 15 de Junho de 1922:

Enquanto não pensar, em vão tentaremos quebrar os grilhões para a nossa independência individual; a mulher é escrava; dependente do salário, do homem, do seu capital. Assim é impossível a libertação. Seu cérebro foi considerado infantil pelo egoísmo masculino dos ancestrais. [...] A brasileira ardente, altiva, inteligente, idealista, generosa, num impulso final, por entre relâmpagos da consciência adormecida, perceberá. [...] Faltam-nos escolas. Faltam-nos educadores na acepção mais ampla da expressão. Faze-los nascer deste mesmo povo - eis o que é preciso. (Moura apud Mendes, 2010, p.10).

Na peça, em diálogo entre o Coronel e Laura, fica clara a força de emancipação derivada da educação:

CORONEL - Ora, eis aí a consequência de uma mulher letrada! Se fosses uma camponesa analfabeta como as tuas companheiras, seguirias as ordens de teu pai, que visam a tua felicidade, sem tiradas dramáticas. Vejo bem teu alvo, minha sabichona, e é precisamente porque o vejo, que me esforço pelo teu consórcio.
LAURA - Senhor Coronel, pobre, subalterna, embora por um acaso de fortuna, não lhe assiste o direito de me insultar; é covarde essa arrogância em face de um ser que julgamos frágil. (Fóscolo apud Vargas, 2009, p.66)

No Brasil, é notável a participação das mulheres na educação anarquista, direcionada a todos, inclusive (mas não somente) às próprias mulheres. Geralmente em segundo plano nos papéis administrativos, elas assumem o protagonismo nas ações educacionais e culturais.

Laura, em O Semeador, é a "fada benéfica" que difunde "prodigamente a instrução, luz do cérebro, sobre as inteligências infantis." Nas palavras de Júlio, é Laura, como ele, uma semeadora:

\begin{abstract}
JÚLIO - [...] nestes campos a semear, com uma abnegação sublime, o gérmen do Saber, esses primeiros rudimentos que são a estrada conduzindo à conquista de um paraíso sonhado. E não é o óbolo azinhavrado com que te retribuem os mais favorecidos da sorte o teu sustentáculo nessa missão excelsa, mas sim a ânsia de desvendar a um mundo novo a miragem de um futuro de paz. (Fóscolo apud Vargas, 2009, p.21)
\end{abstract}

Esse papel é bastante condizente com aquele historicamente assumido pela mulher anarquista, engajada na educação libertária.

Paralelamente à questão educacional, desenvolve-se na peça, pelo viés do amor entre Laura e Júlio, a defesa do amor livre e devotado à causa revolucionária, em oposição ao casamento, instituído em prol de interesses econômicos.

A defesa do amor livre, presente no discurso anarquista em geral, é tomada com veemência pelas anarcofeministas. Anna de Castro Osório, em 1907, compara o casamento à prisão, em texto publicado no jornal A terra livre (cf. Mendes, 2010, p.217). Antro da submissão feminina, amparado pela religião, o casamento burguês obedece à finalidade de conservar o capital, e estabelece para a mulher uma função ser- 
vil ao homem. Como alternativa libertária, o anarquismo propõe a união estabelecida pelo amor livre.

Na peça, o amor entre Júlio e Laura é pretexto para a reafirmação dos objetivos financeiros do casamento por parte da elite, e sua consequente crítica por parte dos libertários.

ROBERTO - Estão a pensar absurdos: que o senhor Júlio baba-se por ti e que tu estás a morrer de amores por ele e temem que essa fortuna, ganha Deus sabe como, venha a cair em tuas mãos.

LAURA - Podem estar tranquilos. Eu e ele desprezamos bastante a riqueza e não nos seduz uma ambição vil. Desejava ser simplesmente uma companheira, uma auxiliar nessa sementeira do bem, porque nos seus sonhos de reformador sinto a crisálida de regeneração social e no afã generoso em prol da nova ideia, vejo a miragem de um paraíso para os desprotegidos, lutando e sofrendo a séculos a perene injustiça. (Fóscolo apud Vargas, 2009, pp.52 - 53)

Paralelamente às questões anarquistas, entretanto, deve-se notar que o texto é fruto do próprio tempo. Em diálogo com Laura, que se diminui por ser mulher, Júlio a exalta, mas os atributos femininos dignos de exaltação seguem sendo a maternidade e o amor, conforme se lê abaixo:

LAURA - Nós, as mulheres, entes fracos, relegados em segundo plano, não alcançaremos jamais o nível moral dos homens.

JULIO - É pelo amor, fonte sacrossanta do bem, que a mulher se dignifica. Não é débil o ser que sustenta essa luta homérica - a criação de um filho desde o berço á puberdade, e que sempre, através da existência, essa rude batalha, agrilhoada a uma inferioridade injusta, que o homem lhe impôs, se devota, mãe ou companheira, a quem a acompanha com uma dedicação de ente bom e forte. E quando a mulher é como tu... (Fóscolo apud Vargas, 2009, p. 20)
Essa preocupação com a mulher como sustentação da família e sua função na criação dos filhos é característica do pensamento da época, nos diversos meios do pensamento. Foram esses parâmetros, inclusive, que direcionaram as primeiras conquistas legais operárias relativas ao trabalho feminino, uma vez que atendiam ao interesse do proletariado sem causar grandes prejuízos aos empresários. (cf. Venâncio, 2001, p.190).

\section{A Bandeira Proletária, de Mário Spagnolo}

A segunda peça, publicada em 1922, drama em três atos, de autoria de Mario Spagnolo ${ }^{7}$, é a que se situa mais precisamente num ambiente fabril. Ainda assim, as mulheres que nela aparecem não são operárias: Rosa trabalha como lavadeira, e Gertrudes vive da exploração de Rosa. Gertrudes, alcoólatra e vítima do sistema capitalista, não levanta questões especificamente femininas, mas questões gerais relativas às pessoas corrompidas pelo sistema.

Já Rosa, amada do libertário Paulo, é tratada como vítima de sua própria ingenuidade. Caracterizada como "ingênua", ela se deixa corromper pela delicadeza de Fernandes, o capitalista rico e mal intencionado, e pelas pressões de Gertrudes, que a explora às custas de a ter criado. Casada com Paulo, acaba deixando-se tomar por concubina de Fernandes, em troca de dinheiro e conforto, enquanto Paulo passa seis meses na cadeia.

A trama desenrola-se a ponto de Rosa tomar conhecimento de seu próprio passado, descobrindo-se vítima da maldade de Gertrudes. Após desmascará-la, ao buscar amparo em Fernandes, descobre nele um covarde, que a abandona para devolvê-la ao marido, depois de privá-la de sua "honra". Apresentadas todas as revelações, Rosa se dispõe a acompanhar Paulo pela causa no movimento anarquista:

\footnotetext{
7 Segundo Vargas (2009, p. XIX) "sabe-se pouco de sua vida - residia no bairro Belenzinho, em São Paulo. Foi vidreiro, passando depois a alfaiate. Figura afável estava, no entanto, sempre pronto a enfrentar os inimigos, quando necessário".
} 
ROSA (ajoelhando-se aos seus pés) - Ah, Paulo, uma tua palavra e serei uma mulher livre de preconceitos... fui vítima da miséria humana e reconheço agora, bem tarde, a inutilidade e inconsequência das personalidades dos grandes. Quero seguir-te, quero morrer em prol de uma causa que me redime e mais aos meus irmãos de infelicidade.

PAULO (com um sorriso de triunfo e comovido, abraça-a com força e beija-a na fronte) - Eu não podia enganar-me! [...] Segue-me, pois. É a hora da grande luta. (Spagnolo apud Vargas, 2009, pp.155/156)

As questões feministas estão longe de ser principais nessa peça. Ao contrário, percebe-se o amor do homem revolucionário por uma mulher como um risco à revolução: inicialmente paralisado pelo amor platônico, Paulo é ironizado pelo companheiro quanto a seu desejo de casar e constituir família:

MÁRIO: Eis o ponto. Casar-se, não
é assim? Constituir uma família para
a ilusão da verdadeira felicidade; ter
filhinhos, companheira, enfim, ter al-
guém com quem partilhar as alegrias
ou as dores futuras. É um lenitivo, é...
enfim, uma ideia que eu duvido vê-
la realizada. (Spagnolo apud Vargas,
2009, p. 94).

Após o casamento, a ingenuidade da mulher a leva a ser vítima da crueldade do sistema. Como vítima arrependida, ela pode enfim ser perdoada, associando-se como companheira na luta libertária.

A questão da ingenuidade toca, por outro viés, a necessidade da educação feminina defendida pelo anarquismo e também pelo anarcofeminismo. No mesmo discurso citado anteriormente, Maria Lacerda de Moura afirma, sobre a mulher: "Cumpre desembaraça-la das peias que a encarceram mentalmente. Enquanto não souber pensar será instrumento passivo em favor das instituições do passado." (Moura apud Leite, 1984, p.20).

Rosa é vítima de todo um sistema, privada de educação e meios de emancipação intelectual e social, e por isso se deixa iludir e acaba por trair o marido. Sutilmente, a peça acaba por defender que a traição é resultado de sua condição de vítima do sistema e por isso deve ser perdoada, e juntar-se à causa maior, a revolução. A defesa, como na primeira peça, é de que amor e causa revolucionária sejam igualmente importantes para a associação entre um homem e uma mulher. Também a necessidade de uma educação libertária, embora não explicitada, fica patente, diante da transformação da mulher "ingênua" em mulher consciente de seu papel e agente na organização social, algo que viria através de uma ação direta com apoio mútuo, um ato revolucionário.

Uma mulher diferente, de Pedro Catallo

Na terceira peça, de 1945, em três atos, de autoria de Pedro Catallo ${ }^{8}$, o tema da mulher é foco central. Em Uma Mulher Diferente, a protagonista, Elena, "diferente" do padrão imposto às mulheres, já representa a mulher anarcofeminista. As outras personagens mulheres estão mais próximas do padrão ditado pela sociedade; são elas: Valeriana, a Senhora Rica e sua Filha, Duas Moças, e a Enfermeira (assim denominadas no rol das personagens).

O próprio autor, em um pequeno prefácio à peça, explica sua "finalidade humana e instrutiva":

Pensamos que a mulher que, por qualquer circunstância, seja obrigada a entregar sua virgindade não deve considerar-se inferior ao seu estado primitivo. Deve capacitar-se e persuadir-se que seus dotes físicos e morais continuam intactos, e não deve eximir-se da luta social, para a conquista de uma vida digna e honesta. (Catallo apud Vargas, 2009, p. 162).

8 "A carreira teatral de Pedro Catallo teve inicio em 1928, quando trabalhava numa oficina dos 'Calçados Luís XV'. Um companheiro, Afonso Festa, convidou-o para tomar parte num grupo de teatro amador, o Grupo Teatral da União. De origem italiana, chegara a São Paulo, vindo da Argentina, aos dezessete anos de idade."(Vargas, 2009, p. XXII). 
O enredo gira justamente em torno à questão da perda da virgindade (um "bem" valorizado e exaltado dentro da moral burguesa), seu significado diante dos preconceitos sociais e o enfrentamento desses preconceitos pela protagonista, Elena. A peça começa com uma dupla negociação: Elena é solicitada a ir ao encontro do ex-patrão, Ricardo, um rico industrial, que apresenta desejos sexuais por sua ex-funcionária. Assim, ele propõe a Elena a libertação de seu pai, com apenas um telefonema, em troca de uma noite de sexo com ela. Importante ressaltar que o pai de Elena se encontra preso por ter sido acusado de roubar o Sr. Ricardo. Entretanto, esta prisão foi uma armação planejada pelo mesmo para usá-la como chantagem e persuadir Elena devido ao interesse sexual.

Elena, sem alternativa, aceita o negócio em troca da liberdade do pai. Quando o pai de Elena, já em liberdade, descobre, pela maledicência que já corre a cidade, qual foi a moeda da troca, ele renega a filha alegando ter sido traído por ela. Ricardo, apaixonado por Elena e arrependido, para reparar sua honra, propõe a ela o casamento, que Elena recusa, dizendo que pretende "viver", pois, uma das questões anarcofeministas é o amor livre, a mulher podendo decidir sobre suas relações, não sujeitando seus ideais em troca de bem estar material e status. Sua recusa ao casamento causa ainda maior tristeza a seu pai, que acredita que a virgindade é a dignidade da mulher. Elena resolve ir embora da casa em que foi acolhida, como meio de aliviar sua angústia e a de seu pai e não causar transtornos a Ludovico, o músico anarquista que a acolheu quando o pai dela se encontrava preso e sofre ameaças de perder suas alunas pela presença de Elena em sua casa.

ELENA - [...] Eu não creio que a dignidade, o caráter e o valor de uma mulher possam medir-se por um simples véu anatômico ou por um ato esporádico e acidental. (Catallo apud Vargas, 2009, p. 262).
Passam-se dois anos depois que Elena foi embora da casa de Ludovico. No ato final, a reviravolta: Elena é nomeada diretora do setor de órfãos de uma maternidade. Ao reencontrá-la, os velhos amigos conhecem o filho de Elena, criança concebida na noite em que ela esteve com Sr. Ricardo. Este acaba por descobrir a existência da criança e insiste em vê-la, até mesmo alega recorrer aos tribunais:

ELENA - E com testemunhas falsas, como quando o senhor mandou meu pai para o cárcere [...] Os tribunais! Os homens de dinheiro resolvem tudo nos tribunais. Eu me pergunto qual é o tribunal que pode obrigar-me a dizer que aqui há um filho que é seu? (idem, p.310/311).

O que vemos é o quanto Elena consegue manter seus ideias e conquista seu lugar com dignidade na sociedade, não precisando mais se submeter às imposições de ninguém. No entanto, com sua generosidade e fraternidade, Elena consegue fazer com que o Sr. Ricardo reveja suas atitudes e se torne um contribuinte do orfanato em que é diretora, mas deixa claro que toda a contribuição recebida dele será dividida entre todas as crianças, sem distinção.

Mais adiante, leem-se os principais discursos explicitamente elaborados contra o casamento, e a favor da família e da maternidade.

Em um diálogo com o Doutor, com quem Elena mantém no momento relacionamento amoroso, e que lhe pede em casamento, à sua pergunta sobre "por que tanto temor ao matrimônio", Elena responde:

ELENA- Porque o matrimônio destrói a candidez e a beleza que envolvem as almas que se querem bem. $\mathrm{O}$ matrimônio confunde o amor com a cozinha, as contas com o idílio, as premências grosseiras da vida com a ternura sequiosa dos sentimentos, tornando tudo banal e sem encantos. DOUTOR- Você então é contra a família?

ELENA- Não, não sou contra a fa- 
mília. Tenho um filhinho que é toda a minha vida e levo você no coração. Mas as pessoas conservam muito ainda da luta brutal dos tempos primitivos. No matrimônio, esta luta renova-se. Não se procura a cooperação, quer-se o domínio; não se mantém o respeito, professa-se a indiferença. E, nessa porfia desastrosa, cada cônjuge emprega as armas favoritas para garantir-se a hegemonia do lar. (idem, p.285)

Mais adiante, no mesmo diálogo, Elena questiona a ideia de que o casamento deva durar para sempre:

DOUTOR - Esperava ter você a meu lado.

ELENA - E não estou?

DOUTOR - A meu lado e minha para sempre.

ELENA - Para sempre? (rindo) $\mathrm{Ah}$ !Ah!Ah!... não diga bobagem. Ninguém sabe o que será amanhã. Você não é feliz assim? Por que destruir esses momentos felizes, que é o único que a vida pode nos dar? DOUTOR - Não quero momentos felizes, quero que toda a minha vida seja feliz.

ELENA - É um desejo justo e humano e farei tudo para que você o seja. (idem, p.287)

Pressionada a aceitar o neto de uma senhora de sociedade, que está ainda por nascer, Elena esclarece a finalidade do hospital. Nesse discurso, ressaltamos a glorificação da maternidade:

ELENA - [...] Este hospital destinase a uma finalidade social e não à conveniência de famílias. Seu fundamento primordial é glorificar a maternidade que nada tem de detestável ou de vergonhoso. Aceitamos crianças castigadas pela orfandade e as que a inclemência humana atira para a rua como trapos. Todavia, jamais seremos cúmplices da covardia de certas mães que, podendo manter os seus filhos, desfazem-se deles por puros preconceitos. (idem, p.305)
Cabe comentar ainda, quanto ao título da peça, que Elena é a "mulher diferente", construída como heroína da história. Isso fica latente no contraste com as outras mulheres da peça: Valeriana, tem por desejo casar-se, é generosa e tenta convencer Elena a se casar também; a Senhora Rica e as Duas moças são representadas como conservadoras da moral cristã e burguesa, responsáveis pela difamação de Elena e sua saída da casa; a Enfermeira, caracterizada como viúva, aparece brevemente, associada a Elena em seus propósitos de fraternidade. A ênfase, com relação às questões da mulher, está colocada principalmente sobre o relacionamento conjugal, as funções familiares e a educação.

Essa característica remete à representação da mulher, na época, principalmente nos papéis de mãe e esposa. Isso reforça de alguma maneira, o que se atesta nas primeiras legislações trabalhistas da época: a preocupação em resguardar esses papéis da mulher, privilegiando-os com relação ao trabalho fabril, e mantendo os homens como mão de obra principal nas fábricas (cf. Venâncio, 2001). 


\section{REFERENNCIAS}

CLEYRE, Voltairine De. Liberdade, feminismo e o Estado - anarquismo e tradições americanas, Ação Direta. SP. Cultura Vozes, $\mathrm{n}^{\circ} 2$ - março/abril de 2001. Vera Lucia Mello Joscelyne (trad.).

COSTA, Caio Túlio. O que é anarquismo? São Paulo. Ed: brasiliense, 1998.

CUNHA, Antônio Geraldo. Dicionário de etimologia Nova Fronteira da língua portuguesa. São Paulo: Nova Fronteira, 1997, p. 44. ANARQUIA (Verbete).

FÓSCOLO, Avelino; SPAGNOLO, Marino; CATALLO, Pedro. VARGAS, Maria Thereza (ed.). Antologia do teatro anarquista. SP: Martins Fontes, 2009.

MALATESTA, Errico. A Anarquia. São Paulo Ed. Imaginário, 2001.

MENDES, Samantha Colhado. As mulheres anarquistas na cidade de São Paulo (1890-1930). 2010. 254f. Dissertação. Programa de Pós-graduação em História, Direito e Serviço Social. Universidade Estadual Paulista “Júlio de Mesquita Filho”, Franca (SP), 2010.

As mulheres anarquistas e o teatro operário na cidade de São Paulo.

Para entender a história. Ano 2. Vol. fev. s.d..Série 16/2 - p. 1-16. Disponível em: http:/ / fabiopestanaramos.blogspot.com.br/2011/02/as-mulheres-anarquistas-e-o-teatro.html Acesso: 17 de jan. 2013.

NETTLAU, Max. História da anarquia: das origens ao anarco - comunismo. São Paulo. Ed. Hedra, 2008. Organização e introdução de Franz Mintz e tradução de Plínio Augusto Coelho.

PASSETTI, Gabriel. Cultura no Brás no Início do Século XX: Teatro Anarquista e Cinema Burguês. Klepsidra: Revista vitural de história. N. 1, 2000. Disponível em: http:/ / dialnet.unirioja.es/servlet/articulo?codigo=1263906. Acesso: 20 fev. 2013.

VENÂNCIO, Giselle Martins. Lugar de mulher é... na fábrica. Estado e trabalho feminino no Brasil: 1910-1934. História: Questões E Debates. Curitiba, n. 34, p. 175-200, 2001. Editora da UFPR. 